\title{
Aktivitas olahraga terhadap kelincahan
}

\section{Sports activities for agility}

\author{
Dhani Agusni Zakaria', Silvy Juditya², Gugun Gunawan³, Muhammad \\ Abdul Wahid ${ }^{4}$ \\ 1,2,3,4 Program studi PJKR, STKIP Pasundan, Cimahi, Jawa Barat, 40512, Indonesia
}

\begin{abstract}
Abstrak
Tujuan dalam penelitian ini adalah meningkatkan kelincahan siswi di SMK Tunas Bangsa dengan penerapan olahraga tradisional hadang dan olahraga modern handball. Metode penelitian yang digunakan adalah Experimen dengan desain penelitian yaitu the modified group pre-test post-test design. Populasi yang diambil adalah siswa kelas XI, sedangkan sampel yang diambil adalah siswi kelas XI Akuntansi 2 yang berjumlah 28 orang. Pembagian kelompok menggunakan teknik Ordinal Pairing (ABBA). Instrumen yang digunakan berupa tes shuttle Run (Tes lari bolak-balik). Data memperlihatkan hasil tes awal dan tes akhir kelincahan untuk kelompok olahraga tradisional mengalami peningkatan sebesar 0,86. Karena, t hitung < t tabel pada taraf signifikan 5\% $(-0,53<$ 2,16), sehingga terdapat peningkatan yang signifikan pada kelincahan siswi kelompok olahraga tradisional. Kemudian pada olahraga handball mengalami peningkatan sebesar 0,13 . Oleh karena, $\mathrm{t}$ hitung $<\mathrm{t}$ tabel pada taraf signifikan $5 \%(-1,12<2,16)$ sehingga terdapat peningkatan yang signifikan pada kelincahan siswi kelompok olahraga modern. Sehingga dapat disimpulkan bahwa jenis penerapan olahraga tradisional lebih memberikan peningkatan pada kelincahan..
\end{abstract}

Kata kunci: Kelincahan, hadang, handball.

\begin{abstract}
The purpose of this study was to increase the agility of female students at SMK Tunas Bangsa by applying traditional hadang sports and modern handball sports. The research method used was an Experiment with a research design that is the modified group pretest post-test design. The population taken was class XI students, while the sample taken was class XI Accounting 2 students, amounting to 28 people. The division of groups using the Ordinal Pairing (ABBA) technique. The instrument used was a shuttle Run test. Data shows the results of the initial test and the final agility test for traditional sports groups increased by 0.86. Because, $t$ count $<t$ table at a significant level of $5 \%(-0.53<2.16)$, so that there is a significant increase in the agility of female students of traditional sports groups. Then in the handball sports increased by 0.13. Therefore, t arithmetic <t table at a significant level of $5 \%(-1.12<2.16)$ so that there is a significant increase in the agility of students of modern sports groups. So it can be concluded that the type of application of traditional sports gives more increase in agility.
\end{abstract}

Keywords: Agility, hadang, handball.

\section{PENDAHULUAN}

Gerak adalah ciri kehidupan, maka dari itu manusia meski meningkatkan gerak sebagai ciri kehidupan yang penting melalui aktivitas pendidikan jasmani. Pendidikan 
jasmani pada dasarnya mengajarkan tentang aktivitas gerak pada anak usia sekolah yang memiliki capaian berupa aspek psikomotor (Silvy Juditya; Ikhlasul, 2017). Keterampilan gerak secara tidak langsung dapat berpengaruh pada perkembangan kemampuan motoric (Rismayanthi, 2013). Namun pada kondisi yang ada di lapangan, masih ditemukan kendala kemapuan gerak pada anak hal ini disebabkan banyak hal diantaranya kegemaran mereka dalam bermain gadget, karena menurut mereka gadget merupakan sebuah maninan yang menarik (Pebriana, 2017). kegemaran pada gadget tidak bisa pungkiri karena adanya dampak dari kemajuan teknologi (Daryanto Setiawan, 2017). (Castelluccio, 2007) menungkapkan bahwa gadget adalah sebuah alat atau instrument yang kecil yang pada dasarnya memiliki tujuan atau fungsi yang sangat praktis dan berguna, gadget diciptakan untuk memberikan kemudahan seseorang dalam mempergunakan media sebagai alat komunikasi (Pebriana, 2017). kegemaran anak pada gadget secara berlebihan akan memberikan dampak pada kemampuan interaksi social, berdampak pada perilaku (Fauziah, 2013), berdampak pada karakter anak (Chusna, 2018), dan yang paling parahnya akan berdampak pada kemampuan gerak dan tumbuh kembang anak (Yudiningrum, 2011). Banyak cara bisa dilakukan untuk meningkatkan kemapuan anak, baik dari segi perilaku, interkasi, karakter, tumbuh kembang dan perilaku anak yaitu salah satunya dengan penerapan olahraga tradisional dikalangan anak-anak (Uswatun Hasanah, n.d.), (Munawaroh, 2017), (Yulingga Nanda Hanief, 2015), (Efendi, 2015), (Yudiwinata \& Handoyo, 2014). (Suprayitno, 2014) olahraga tradisonal merupakan salah satu bentuk kegiatan olahraga yang mulai berkembang dikalangan masyarakat modern dimana di dalam olahraga tradisional cukup kental dengan tradisi budaya setempat. Selain olahraga tradisional yang dapat meningkatkan kemampuan gerak dan karakter seseorang, olahraga modernpun mampu meningkatkannya (Desy Anggar Aditia, 2015).

Olahraga merupakan segala kegiatan yang sistematis untuk mendorong, membina, serta, mengembangkan potensi jasmani, rohani, dan sosial. Berdasarkan (UU No 3 Tahun 2005, 2005) ruang lingkup olahraga meliputi kegiatan: (1) olahraga pendidikan, (2) olahraga rekreasi, dan (3) olahraga prestasi. Salah satu dampak dari aktivitas olahraga baik olahraga tradisional dan olahraga modern yaitu terbentuknya kelincahan pada para pelakunya (Maharani Fatima Gandasari, 2019). (Widiastuti, 2015)) agility atau kelincahan adalah kemampuan untuk mengubah arah atau posisi tubuh dengan cepat yang dilakukan bersama-sama dengan gerakan lainnya. (Mylsidayu, Apta \& Kurniawan, 2015) kemampuan untuk mengubah arah dan posisi tubuh atau bagian- 
bagiannya secara tepat dan tepat. Sumber lain mengatakan bahwa agility adalah kemampuan untuk mengubah arah dengan cepat dan fleksibel ketika sedang bergerak.

Sudah banyak orang berbicara mengenai keterhubungan antara permainan olahraga tradisional dengan perkembangan perilaku (Widodo \& Lumintuarso, 2017), (Hadiyah \& Nurhayati, 2013) olahraga tradisional terhadap karakteristik siswa, selain itu banyak pula yang berbicara mengenai katerkaitan antara penerapan olahraga terhadap pembentukkan karakter (Maksum, 2005), (Desy Anggar Aditia, 2015). Bahkan sudah banyak yang berbicara mengenai penerapan olahraga tradisional dengan kemampuan gerak pada anak (Pratiwi \& Kristanto, 2014), (Kusmiati \& Sumarno, 2018). namun pada penelitian ini lebih menitik beratkan kepada membandingkan pengaruh aktivitas olahraga tradisional dan aktivitas olahraga modern terhadap kelincahan siswa.

\title{
METODE
}

Metode penelitian yang akan digunakan dalam penelitian ini adalah metode penelitian Eksperimen. variabel independen pada penelitian ini yaitu olahraga tradisional dengan olahraga modern sedangkan untuk variabel dependent yaitu kelincahan siswa. Desain yang digunakan dalam penelitian ini yaitu "the modified group pre-test post-test design". Rancangan ini dapat digambarkan sebagai berikut:

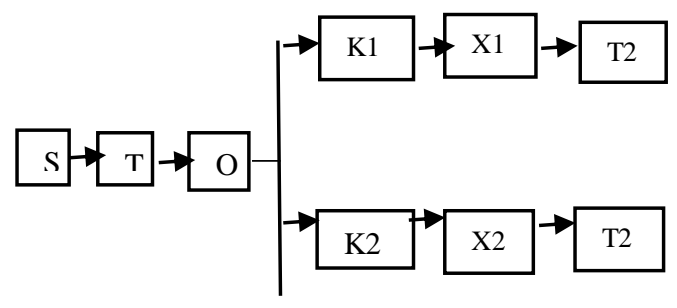

\author{
Gambar 1 \\ Keterangan : \\ the modified group pre-test post-test design \\ S : Sampel \\ T 1 : Tes awal (Pretest) Shuttle Run 6x10 \\ O P : Ordinal Pairing $\neg($ A-B-B-A) \\ K 1 : Kelompok eksperimen A (olahraga tradisional) \\ K 2 : Kelompok eksperimen B (olahraga modern) \\ $\mathrm{X} 1$ : Treatment latihan olahraga tradisional \\ X 2 : Treatment latihan olahraga modern \\ T 2 : Tes akhir (Posttest) Shuttle Run 6x10 \\ Populasi yang peneliti ambil dalam penelitian ini adalah siswa-siswi yang
}


didominasi oleh siswi perempuan diseseuaikan dengan permasalahan yang ingin peneliti angkat yaitu kelas XI di SMK Tunas Bangsa yang terdiri dari 2 kelas jurusan akuntansi dan 2 kelas jurusan Administrasi yang berjumlah 109 orang. Penelitian ini menggunakan teknik sampling yaitu Cluster Sampling (area sampling). Sugiyono, "teknik sampling daerah digunakan untuk menentukan sampel bila objek yang akan diteliti atau sumber data sangat luas." Setelah diundi maka terpilihlah satu kelas dengan karakteristik yang sama, yaitu kelas XI Akuntansi 2 yang berjumlah 28 orang sebagai sampel pada penelitian ini. Kemudian setelah diketahui bahwa sampel dalam penelitian ini adalah kelas XI Akuntansi 2 berjumlah 28 orang. Langkah selanjutnya peneliti membagi sampel menjadi 2 kelompok dengan model ordinal pairing. Berikut ini langkah-langkah pembagian kelompok dengan cara ordinal pairing:

a. Seluruh subjek diberi tes awal Shuttle run 6 x 10 meter

b. Hasil dari tes kemudian dirangking mulai dari nilai tertinggi sampai yang terendah.

c. Agar subjek seimbang teknik pembagian kelompok ditentukan dengan rumus (A B B A).

d. Kelompok A meliputi rangking 1,4,5,8 dan seterusnya, sedangkan kelompok B meliputi rangking 2,3,6,7 dan seterusnya.

Untuk menentukan kelompok yang menerima treatment 1 atau 2 peneliti menggunakan random assigment. Random assignment atau teknik pembagian secara acak, hasilnya kelompok 1 berjumlah 14 orang menerima treatment olahraga tradisional berupa permainan hadang, dan kelompok 2 berjumlah 14 orang menerima treatment olahraga modern yaitu permainan handball. Karena menurut Sugiyono "untuk penelitian eksperimen yang sederhana maka jumlah sampel antara $10 \mathrm{~s} / \mathrm{d} 20$.

Dalam penelitian ini peneliti menggunakan jenis instrument tes yaitu tes lari bolak-balik 6 x 10 meter. Intrument untuk mengukur kelincahan. Analisis data yang dicari diantaranya yaitu rata-rata, simpangan baku, normalitas, homogenitas, dan pengujian hipotesis.

\section{HASIL DAN PEMBAHASAN}

Tabel 1

Hasil Penghitungan Uji Normalitas Tes Awal Dan Tes Akhir

\begin{tabular}{lllll}
\hline No. & Kelompok & Lo $_{\text {hitung }}$ & $\mathrm{L}_{\text {tabel }}(\dot{\alpha} 0,05)$ & Kesimpulan \\
\hline 1 & $\begin{array}{l}\text { Pre-test Olahraga } \\
\text { Tradisional }\end{array}$ & 0,098 & & Normal \\
2 & $\begin{array}{l}\text { Post-test Olahraga } \\
\text { Tradisional }\end{array}$ & 0,089 & & Normal \\
3 & $\begin{array}{l}\text { Pre-test Olahraga } \\
\text { Modern }\end{array}$ & 0,141 & 0,227 & Normal \\
4 & $\begin{array}{l}\text { Post-test Olahraga } \\
\text { Modern }\end{array}$ & 0,173 & & Normal \\
\hline
\end{tabular}


Hasil perhitungan menggunakan Microsoft Office Excel 2016, pada tabel 1 dijelaskan bahwa proses penghitungan diperoleh Lo hitung tes awal olahraga tradisional sebesar 0,098 dan tes akhir 0,089 kedua data tersebut berdistribusi normal karena kurang dari Ttabel $(0,227)$. Kemudian Lo hitung tes awal pada olahraga modern sebesar 0,141 dan tes akhir sebesar 0,173 kedua data tersebut berdistribusi normal karena kurang dari Ttabel $(0,227)$. Kriterianya adalah : Terima hipotesis jika Lo $<$ Ló $=$ normal dan menolak hipotesis jika Lo > Ló = Tidak normal. Maka dapat disimpulkan bahwa data tes awal dan tes akhir kedua perlakuan tersebut berdistribusi normal.

Tabel 2

\section{Ringkasan Uji Homogenitas}

\begin{tabular}{llll}
\hline Kelompok & Fhitung & $\mathrm{F}_{\text {tabel }}$ & Keterangan \\
\hline Olahraga & 2,13 & & Homogen \\
$\begin{array}{l}\text { Tradisional } \\
\text { Olahraga }\end{array}$ & 2,23 & 2,55 & Homogen \\
Modern & & & \\
\hline
\end{tabular}

Kriteria pengujian uji homogenitas adalah : tolak hipotesis (H0), jika F > F $\alpha$; dk n-1 dalam hal lain H0 diterima. Hasil dari pengujian menunjukan nilai Ftabel 0.05 (13:13) tidak ada maka penulis menggunakan nilai Ftabel (14:13) yaitu sebesar 2,55 (taraf nyata $\alpha 0.05$ ). Dari hasil penghitungan Fhitung, dikemukakan nilai $\mathrm{F}$ hitung tes awal dan akhir berturut-turut yaitu 2,13 dan 2,23 lebih kecil dari pada Ftabel (14:13) yaitu 2,55. Data tes untuk kelompok olahraga tradisional $(2,13<2,55)$, dan data tes olahraga modern $(2,23<2,55)$, maka hipotesis dapat diterima, dengan kata lain kedua data tersebut homogen.

\section{Tabel 3}

Hasil Uji T Kelompok Olahraga Tradisional

\begin{tabular}{llll}
\hline Kelompok & Rata-rata & $\mathrm{t}_{\text {hitung }}$ & $\mathrm{t}$ tabel \\
\hline $\begin{array}{l}\text { pre-test } \text { kelompok } \\
\text { olahraga }\end{array}$ & 20,98 & & \\
$\begin{array}{l}\text { tradisional } \\
\text { post-test }\end{array}$ & & $-0,53$ & 2,16 \\
$\begin{array}{l}\text { kelompok olahraga } \\
\text { tradisional }\end{array}$ & 20,12 & & \\
\hline
\end{tabular}

Kriteria pengujian: terima hipotesis jika $-\mathrm{t}(1-1 / 2 \alpha)<\mathrm{t}<\mathrm{t}(-1 / 2 \alpha)$, $\mathrm{dk}(\mathrm{n}-1)$ dalam hal lain hipotesis (H0) ditolak. Berdasarkan tabel di atas, didapatkan rata-rata nilai pre-test kelompok olahraga tradisional sebesar 20,98 dan nilai rata-rata post-test sebesar 20,12 sehingga mengalami peningkatan sebesar 0,86 . Oleh karena, $\mathrm{t}$ hitung $<\mathrm{t}$ tabel pada taraf signifikan $5 \%(-0,53<2,16)$ sehingga dapat disimpulkan bahwa terdapat peningkatan yang signifikan pada kelincahan siswi kelompok olahraga tradisional. 


\section{Tabel 4}

\section{Hasil Uji T Kelompok Olahraga Modern}

\begin{tabular}{llll}
\hline Kelompok & $\begin{array}{l}\text { Rata- } \\
\text { rata }\end{array}$ & $\mathrm{t}$ hitung & $\mathrm{t}$ table \\
\hline $\begin{array}{l}\text { pre-test } \\
\text { kelompok }\end{array}$ & 20,98 & & \\
olahraga & & & \\
modern & & $-1,12$ & 2,16 \\
post-test & & & \\
kelompok & 20,84 & & \\
$\begin{array}{l}\text { olahraga } \\
\text { modern }\end{array}$ & & \\
\hline
\end{tabular}

Kriteria pengujian: terima hipotesis jika $-\mathrm{t}(1-1 / 2 \alpha)<\mathrm{t}<\mathrm{t}(-1 / 2 \alpha), \mathrm{dk}(\mathrm{n}-1)$ dalam hal lain hipotesis (H0) ditolak. Berdasarkan tabel di atas, didapatkan rata-rata nilai pre-test kelompok olahraga modern sebesar 20,98 dan nilai rata-rata post-test sebesar 20,84 sehingga mengalami peningkatan sebesar 0,13 . Oleh karena, $t$ hitung $<\mathrm{t}$ tabel pada taraf signifikan $5 \%(-1,12<2,16)$ sehingga dapat disimpulkan bahwa terdapat peningkatan yang signifikan pada kelincahan siswi kelompok olahraga modern.

Tabel 5

\begin{tabular}{|c|c|c|c|c|}
\hline & Kelompok & Beda & $\mathrm{t}$ hitung & $\mathrm{t}_{\text {tabel }}$ \\
\hline & $\begin{array}{l}\text { kelompok } \\
\text { olahraga hadang } \\
\text { kelompok } \\
\text { olahraga modern }\end{array}$ & 0,73 & 1,55 & 2,056 \\
\hline
\end{tabular}

Batas penerimaan/penolakan hipotesis nol (H0), tolak jika $\mathrm{t} \geq(1-\alpha) ; \mathrm{dk}(\mathrm{n} 1+\mathrm{n} 2$ -2). Ringkasan uji t post-test diketahui hasil belajar kelompok olahraga hadang rata-rata sebesar 0,86 dan rata-rata hasil belajar kelompok olahraga modern 0,13 sehingga dapat disimpulkan bahwa rata-rata hasil belajar kelompok olahraga tradisional lebih besar $(0,73)$ dibandingkan dengan kelompok olahraga modern. Dari tabel tersebut diketahui $\mathrm{t}$ hitung sebesar 1,55 dan $\mathrm{t}$ tabel sebesar 2,056. Jadi nilai $\mathrm{t}$ hitung $<\mathrm{t}$ tabel $(1,55<2,056)$. Dapat disimpulkan bahwa jenis penerapan olahraga tradisional lebih memberikan peningkatan yang signifikan dibandingkan dengan penerapan jenis olahraga modern.

\section{Pembahasan}

\section{Olahraga tradisional terhadap kelincahan}

Dalam meningkatkan kelincahan sebenarnya banyak sekali bentuk pembelajaran yang dapat mendukung termasuk menggunakan model pembelajaran yang seperti olahraga tradisional hadang. Dalam komponen kelincahan ini membutuhkan komponen kordinasi dan keseimbangan yang prima, seorang atlet agar memiliki kelincahan, yakni kemampuan untuk bergerak secepatnya dari satu titik ke titik lainnya, kemudian secara 
tiba-tiba mengubah arah, menghindari atau mengelilingi objek secepatnya memerlukan komponen biomotorik kelincahan. (Marjana, Sudiana, \& Budiawan, 2014) salah satu metode latihan yang bisa dilakukan untuk meningkatkan kelincahan adalah metode latihan Shuttle Run (lari bolak-balik) sasaran daripada metode latihan ini adalah kelincahan dengan mengubah gerak tubuh arah lurus, (Ahmad, 2018) latihan zig zag run mampu meningkatkan kelincahan, (Citra Azhariat Malasari, 2019) kelincahan seseorang dapat ditingkatkan melalui metode latihan zig zag run.

Karakteristik daripada metode latihan dan penjelasan mengenai komponen kelincahan tersebut sejalan dengan karakteristik daripada olahraga tradisional hadang itu sendiri. (Irwanto, 2003) hadang merupakan olahraga tradisional yang tidak mempergunakan alat seperti layaknya olahraga tradisional lainnya. (Dani Nurdiansyah, 2018) mengungkapkan bahwa olahraga tradisional hadang dimainkan oleh dua regu dan setiap regunya terdiri dari 8 orang, hadang ini memiliki tujuan untuk meningkatkan kebugaran jasmani seseorang, diantaranya kelincahan. (Wasi \& Siregar, n.d.) "Melihat dari bentuk permainannya, permainan hadang mengandung unsur-unsur kinestetik dan unsur rekreasinya, anak-anak berlari, melompat, menghindar dengan meliukkan badannya, berjongkok, meloncat dan mengayunkan tangannya". Sehingga treatment olahraga tradisional hadang ini berhasil meningkatkan kelincahan siswi di SMK Tunas Bangsa karena memenuhi syarat daripada komponen-komponen kelincahan juga memiliki karakteristik yang serupa dengan metode latihan peningkatan kelincahan yaitu Shuttle Run (lari bolak-balik).

Melihat dari pemaparan di atas mengenai olahraga hadang mampu meningkatkan kemapuan kelincahan siswa, hal ini sejalan dengan (Dani Nurdiansyah, 2018) yang mengungkapkan bahwa olahraga tradisional mampu berpengaruh pada agility (Kelincahan).

\section{Olahraga modern terhadap kelincahan}

Seperti yang disampaikan sebelumnya bahwa dalam meningkatkan kelincahan banyak sekali bentuk pembelajaran yang dapat mendukung termasuk salah satunya yaitu jenis olahraga modern handball atau bola tangan. Teknik dasar permainan bola tangan adalah bentuk dan pola permainan yang dapat dikatakan merupakan modifikasi dari permainan sepak bola dan bola basket. Pada umumnya permainan bola tangan berjalan dengan tempo yang cepat. Sehingga diperlukan keterampilan yang mendukung dalam permainan ini. Olahraga handball terdiri dari passing, dribbling, dan shooting. Ketika dalam posisi bertahan para pemain akan berusaha untuk merebut bola dengan menghalangi lawan yang menyerang, ketika bola berhasil direbut seketika pemain 
bertahan harus bekerjasama untuk melakukan serangan balik cepat dengan mengalirkan bola dari satu sisi ke sisi yang lain sampai akhirnya melakukan shooting ke gawang lawan. Proses ini sejalan dengan pendapat yang disampaikan oleh Sajoto mengenai kelincahan atau agility, agility adalah kemampuan mengubah arah dengan cepat dan tepat, selagi tubuh bergerak dari satu tempat ke tempat lain. Oleh karenanya, treatment olahraga modern handball berhasil meningkatkan kelincahan siswi di SMK Tunas Bangsa.

\section{Olahraga tradisional dan olahraga modern terhadap kelincahan}

Ketika berbicara aspek kelincahan banyak faktor yang dapat mempengaruhinya, diantaranya bentuk latihan, durasi latihan, karakteristik latihan dan frekuensi ketika melakukan latihan gerak. Ketercapaian hasil pada sebuah aktivitas olahraga tergantung dari aturan yang dilakukannya dan tidak bisa dilakukan secara sembarangan (Prativi \& Artikel, 2013). (Harsono, 1988) mengungkapkan dalam melakukan aktivitas olahraga diperlukan sebuah dosis latihan yang terjabarkan dalam konsep yang harus diperhatikan konsep FITT (Frekuensi, Intensitas, Time, Tipe). Capaian aspek kelincahan pada penelitian ini juga ditunjang daripada perbedaan lapangan dari kedua jenis perlakuan yang diberikan yaitu berupa olahraga tradisional hadang dan olahraga modern handball. Berbicara aspek lapangan olahraga handball memiliki karakteristik lapangan yang umum sebetulnya sehingga pergerakan yang dilakukan siswa tidak begitu intensive, artinya tidak ada penekanan pada siswa untuk bergerak secara aktif, pergerakan secara aktif hanya dilakukan atas kesadaran siswa itu sendiri. Sedangkan pada karakteristik lapang olahraga hadang lapangan berbentuk persegi panjang dengan beberapa garis tengah, yang mana setiap garisnya memiliki fungsi masing-masing. Setiap siswa yang jaga akan menempati tiap garis dengan tugas menghadang lawan agar tidak bisa lewat dengan pergerakan ke samping kanan dan kiri juga ke depan belakang untuk pemain yang menjadi ulung (pemain yang menempati garis tengah), kemudian untuk tim yang bermain mereka harus berlari kemudian menghindari tangkapan lawan dan kembali lagi berlari dari titik akhir ke titik awal, aktivitas ini sejalan dengan metode latihan peningkatan kelincahan yaitu Shuttle Run atau lari bolak-bolak.

Kemudian dari segi pengetahuan, peneliti melakukan pengumpulan informasi mengenai pengetahuan siswa tentang olahraga hadang dan handball melalui teknik wawancara meski secara tidak tertulis, hasilnya sebagian besar siswa mengetahui olahraga hadang daripada olahraga handball untuk siswa yang mengetahui olahraga handball hanya 2 orang dari 28 orang siswa. Sehingga berpengaruh pada pelaksanaan permainan yang mana kelompok olahraga hadang bisa langsung menyesuaikan dengan 
permainan sedangkan kelompok olahraga handball masih harus dibimbing dalam melaksanakannya.

Selanjutnya ditinjau daripada konsep FITT (Frekuensi, Intensitas, Time, Tipe) olahraga hadang seperti disampaikan sebelumnya lebih menuntut siswa untuk senantiasa bergerak, setiap orangnya pasti melakukan perpindahan tempat entah itu tim yang bermain atau pun yang jaga. Sedangkan pada olahraga handball siswa bergerak secara kolektif bersama-sama bahkan ada siswa yang cenderung menunggu yaitu yang berperan sebagai kiper. Selanjutnya ditinjau daripada intensitas gerak olahraga hadang menuntut siswa untuk bergerak secara intensive sehingga beban yang diberikan kepada siswa lebih banyak selain daripada harus berlari siswa dituntut untuk menghindari lawan menjaga keseimbangan tubuh pada saat menghindar dan berlari kembali. Sementara olahraga handball tuntutan gerak hanya pada pemain yang memegang bola saja dia harus berlari dan menjaga keseimbangan dalam melindungi bola kemudian melakukan passing pada pemain lain. Pemain yang lain cenderung hanya berlari dan menunggu bola. Kemudian ditinjau daripada aspek Time, waktu yang diberikan pada umumnya sama yaitu 2x15 menit dengan $1 \mathrm{x}$ istirahat. Time disini tidak berbicara mengenai waktu seara umum tetapi berbicara mengenai waktu daripada setiap pemain dalam bergerak, memang peneliti tidak spesifik dalam mengamati waktu bergerak tiap siswa hanya saja berdasarkan pengamatan dilapangan pada olahraga hadang siswa bergerak secara intensive karena tuntutan tugas gerak daripada olahraga hadang itu sendiri. Sedangkan pada olahraga handball siswa bergerak secara aktif hanya atas kesadarannya sendiri tidak ada tuntutan bahwa setiap pemain harus berlari dan menghindari lawan jika memang tidak memegang bola karena pergerakan pada permainan ini dilakukan secara kolektif atau bersama-sama dan bertumpu pada pemain yang menguasai bola. Kemudian fakta dilapangan menunjukan bahwa penjagaan terhadap pemain yang menguasai bola tidak begitu ketat sehingga mudah dalam melewatinya. Yang terakhir dari konsep FITT yaitu tipe atau karakteristik gerak, telah disinggung beberapa kali diawal mengenai karakteristik gerak, olahraga hadang memiliki karakteristik gerak yang lebih sama dengan metode latihan penigkatan kelincahan yaitu shuttle run dibandingkan dengan olahraga handball.

Berdasarkan dari paparan di atas, sehingga benar adanya jika olahraga tradisional hadang memberi peningkatan yang lebih signifikan dibandingkan dengan olahraga modern handball terhadap kelincahan siswi di SMK Tunas Bangsa.

\section{KESIMPULAN}

Berdasarkan hasil penelitian penghitungan dan analisis data dari hasil pengukuran, maka dapat disimpulkan bahwa Implementasi penggunaan penerapan jenis olahraga 
tradisional memberikan pengaruh yang signifikan terhadap peningkatan kelincahan siswi di SMK Tunas Bangsa. Implementasi penggunaan penerapan jenis olahraga modern memberikan pengaruh yang signifikan terhadap peningkatan kelincahan siswi di SMK Tunas Bangsa. Implementasi penggunaan penerapan jenis olahraga tradisional lebih berpengaruh dibandingkan dengan olahraga modern dalam meningkatan kelincahan siswi di SMK Tunas Bangsa

\section{DAFTAR PUSTAKA}

Ahmad, N. (2018). Pengaruh Latihan Zig Zag Run Terhadap Kelincahan Atlet Pencak Silat Tapak Suci Lebong. Journal Physical Education, Health and Recreation, 2(2), 181. https://doi.org/10.24114/pjkr.v2i2.9589

Castelluccio, M. (2007). Gadget An-Essay.

Chusna, P. A. (2018). Pengaruh Media Gadget Pada Perkembangan Karakter Anak. Dinamika Penelitian: Media Komunikasi Sosial Keagamaan, 17(2), 315-330.

Citra Azhariat Malasari. (2019). PENGARUH LATIHAN SHUTTLE-RUNDAN ZIGZAGRUNTERHADAP KELINCAHAN ATLET TAEKWONDO. 3, 81-88.

Dani Nurdiansyah. (2018). JUARAPENGARUH PERMAINAN TRADISIONAL HADANG TERHADAP AGILITY. JUARA : Jurnal Olahraga, 3(2), 1-7. Retrieved from http://jurnal.upmk.ac.id/index.php/juara

Daryanto Setiawan. (2017). Perkembangan Teknologi Komunikasi Dan Dampaknya Terhadap Kehidupan. Jurnal Pendidikan, X(2), 195-211. https://doi.org/10.1155/2015/146250

Desy Anggar Aditia. (2015). Survei Penerapan Nilai-Nilai Positif Olahraga Dalam Interaksi Sosial Antar Siswa Di Sma Negeri Se-Kabupaten Wonosobo Tahun 2014/2015. Active - Journal of Physical Education, Sport, Health and Recreation, 4(12), 2251-2259. https://doi.org/10.15294/active.v4i12.8799

Efendi, D. I. (2015). Permainan Tradisional Sebagai Media Stimulasi. Didaktika, 13(3), $11-18$.

Fauziah, E. R. (2013). Pengaruh Game Online Terhadap Perubahan Perilaku Anak Smp Negeri 1 Samboja. Lmu Komunikasi, 1(3), 1-16. Retrieved from ejournal.ilkom.fisip-unmul.ac.id

Hadiyah \& Nurhayati. (2013). Pjok | 221. Pembentukan Karakter, 01, 221-227.

Harsono. (1988). Coaching dan Aspek-aspek psikologis dalam coaching. Jakarta: CV. Tambak Kusuma.

Irwanto. (2003). Jenis dan Manfaat Permainan Tradisional. Jakarta: Rineka Cipta.

Kusmiati, A. M., \& Sumarno, G. (2018). Pengaruh Permainan Tradisional terhadap Kemampuan Perseptual Motorik Anak di SDN Margawatu II Garut Kota. TEGAR: Journal of Teaching Physical Education in Elementary School, 1(2), 17. https://doi.org/10.17509/tegar.v1i2.11934 
Maharani Fatima Gandasari. (2019). PENGARUH PERMAINAN OLAHRAGA TRADISIONAL SEPAK BELEG TERHADAP KEMAMPUAN KELINCAHAN ANAK USIA 7-10 TAHUN Maharani Fatima Gandasari. II(April).

Maksum, A. (2005). Olahraga membentuk karakter: fakta atau mitos? Jurnal Ordik, 3(1), $1-10$.

Marjana, W., Sudiana, I. ., \& Budiawan, M. (2014). PENGARUH PELATIHAN SHUTTLE RUN e-Journal IKOR Universitas Pendidikan Ganesha Jurusan Ilmu Keolahragaan. E-Journal IKOR Universitas Pendidikan Ganesha Jurusan Ilmu Keolahragaan, $\quad I, \quad 1 . \quad$ Retrieved from https://ejournal.undiksha.ac.id/index.php/JJIK/article/download/2831/2340\%0A

Munawaroh, H. (2017). Pengembangan Model Pembelajaran dengan Permainan Tradisional Engklek Sebagai Sarana Stimulasi Perkembangan Anak Usia Dini. Jurnal Obsesi: Jurnal Pendidikan Anak Usia Dini, 1(2), 86. https://doi.org/10.31004/obsesi.v1i2.19

Mylsidayu, Apta \& Kurniawan, F. (2015). Ilmu Kepelatihan Dasar. Bandung: Alfabeta.

Pebriana, P. H. (2017). Jurnal Obsesi: Jurnal Pendidikan Anak Usia Dini Analisis Penggunaan Gadget terhadap Kemampuan Interaksi Sosial. Jurnal Pendidikan Anak Usia Dini, 1(1), 8. https://doi.org/10.31004/obsesi.v1i1.26

Prativi, G. O., \& Artikel, I. (2013). Pengaruh Aktivitas Olahraga Terhadap Kebugaran Jasmani. JSSF (Journal of Sport Science and Fitness), 2(3), 32-36.

Pratiwi, Y., \& Kristanto, M. (2014). Upaya meningkatkan kemampuan motorik kasar (keseimbangan tubuh) anak melalui permainan tradisional engklek di kelompok B Tunas Rimba II Tahun Ajaran 2014/2015. Jurnal Penelitian PAUDIA, 3(2), 18-39. Retrieved from http://google.schoolar.com/

Rismayanthi, C. (2013). Mengembangkan Keterampilan Gerak Dasar Sebagai Stimulasi Motorik Bagi Anak Taman Kanak-Kanak Melalui Aktivitas Jasmani. Jurnal $\begin{array}{llll}\text { Pendidikan Jasmani } & \text { Indonesia, } & \text { 64-72. }\end{array}$ https://doi.org/10.21831/JPJI.V9I1.3065

Silvy Juditya; Ikhlasul. (2017). LEARNING BASKETBALL USING TGT MODEL.

Suprayitno. (2014). Peran Permainan Tradisional Dalam Membantu Pertumbuhan Dan Perkembangan Gerak Anak Secara Menyeluruh. Jurnal Ilmu Keolahragaan, 13(2), $38-44$.

Uswatun Hasanah. (n.d.). PERKEMBANGAN KEMAMPUAN FISIK MOTORIK MELALUI PERMAINAN TRADISIONAL BAGI ANAK USIA DINI. Jurnal Pendidikan Anak, Volume 5, Edisi 1, 5(1).

UU No 3 Tahun 2005. (2005). Undang-Undang Republik Indonesia Nomor 3 Tahun 2005 Tentang Sistem Keolahragaan Nasional Dengan. Presiden RI, (1), 1-53.

Wasi, Z., \& Siregar, N. M. (n.d.). PENGARUH PERMAINAN HADANG DAN PERMAINAN TAP JONGKOK TERHADAP KETERAMPILAN GERAK. 101-106.

Widiastuti. (2015). Tes dan Pengukuran Olahraga. Jakarta: Radja Grafindo Persada.

Widodo, P., \& Lumintuarso, R. (2017). Pengembangan model permainan tradisional 
untuk membangun karakter pada siswa SD kelas atas. Jurnal Keolahragaan, 5(2), 183. https://doi.org/10.21831/jk.v5i2.7215

Yudiningrum, F. R. (2011). EFEK TEKNOLOGI KOMUNIKASI ELEKTRONIK BAGI TUMBUH KEMBANG ANAK Firdastin Ruthnia Yudiningrum. EFEK TEKNOLOGI KOMUNIKASI ELEKTRONIK BAGI TUMBUH KEMBANG ANAK Firdastin, 4(1), 1-15.

Yudiwinata, H. P., \& Handoyo, P. (2014). Permainan Tradisional dalam Budaya dan Perkembangan Anak. Paradigma, 02, 1-5.

Yulingga Nanda Hanief, S. (2015). Jurnal sportif • vol. 1 no. 1 november 2015 60. Jurnal Sportif, 1(1), 60-73. 